\title{
Ensino remoto em tempos de Covid-19: percepções de alunos do curso de Letras
}

Fernanda Barboza de Lima ${ }^{\mathrm{i}}$

\begin{abstract}
RESUMO
A pandemia do Covid-19 impeliu universidades a suspenderem suas atividades que, aos poucos, foram transferidas para a modalidade de ensino remoto. Nesse contexto, professores e alunos passaram a conviver com novos formatos de ensino que se propuseram a atenuar os efeitos da interrupção das aulas presenciais. Com o objetivo de nos somar às reflexões e aos estudos que tentam compreender os impactos dessa realidade, propusemo-nos a analisar as percepções que graduandos de Letras da modalidade presencial tiveram do ensino remoto, depois de cursarem disciplinas em uma plataforma virtual de aprendizagem. Os principais resultados apontam a falta de interação presencial como maior desvantagem e a maior autonomia na organização dos estudos como maior vantagem do ensino remoto em comparação ao presencial.
\end{abstract}

Palavras-chave: Ensino presencial; Ensino remoto; Letras.

\begin{abstract}
The Covid-19 pandemic prompted universities to suspend their activities, which were gradually transferred to a remote education setting. In this context, teachers and students began to live with new teaching formats that aimed to mitigate the effects of interrupting face-to-face classes. In order to add our research to the reflections and studies that try to understand the impacts of this reality, we propose to analyze the perceptions that undergraduate students of a Letras Course from the presential modality had about remote teaching after taking courses in a virtual-learning platform. The main results point to the lack of face-to-face interaction as a major disadvantage, and to greater autonomy in the organization of studies as the greatest advantage of remote education in comparison to face-to-face teaching.
\end{abstract}

Keywords: Classroom teaching; Remote teaching; Letras Course.

\footnotetext{
${ }^{\text {i }}$ Professora Adjunta do Departamento de Letras do Campus IV (CCAE) da Universidade Federal da Paraíba (UFPB). | https://orcid.org/0000-0003-0474-6160 | fernandabarboza.ufpb@gmail.com
} 


\section{INTRODUÇÃO}

Uma situação inédita de emergência sanitária internacional, a pandemia ocasionada pelo Covid-19, exigiu que escolas e universidades suspendessem suas atividades por um período indefinido. Entendendo a necessidade de minimizar os impactos dessa lacuna na formação de centenas de universitários dos mais diversos cursos, uma boa parte das universidades públicas brasileiras implantou ou vem implantando o ensino remoto emergencial.

No esteio dessas iniciativas, muitos desafios vêm sendo enfrentados pelas mais diversas instâncias acadêmicas que, em tempo recorde, precisaram capacitar professores e alunos para essa nova realidade. Embora a Educação a Distância (EAD) faça parte do cotidiano de instituições e professores e, por isso, plataformas de ensino on-line não sejam ambientes desconhecidos, é pertinente pontuar alguns fatores que particularizam a educação remota e a diferenciam das experiências já vivenciadas na EAD.

Esse trabalho tem o propósito de discutir esse tema. Após planejamento, organização e realização de uma disciplina de Linguística na plataforma Moodle Classes, da Universidade Federal da Paraíba (UFPB), passamos a observar com inquietação que métodos e formatos já consolidados na EAD precisavam ser repensados no ensino remoto, principalmente porque as escolhas didático-metodológicas a serem realizadas seriam destinadas a um público que vinha do ensino presencial.

Em vista dessa inquietude, propusemos, ao fim das atividades da disciplina, que os alunos produzissem um texto que respondesse à questão: Em comparação ao ensino presencial, quais foram as maiores vantagens e desvantagens do ensino remoto?

Esse trabalho, assim, se propõe a analisar os textos produzidos em resposta a essa questão. Antes disso, porém, discutimos brevemente o avanço tecnológico na vida da sociedade, a influência desse avanço na educação superior e as semelhanças e diferenças entre ensino a distância e ensino remoto.

\section{PERSPECTIVAS TEÓRICAS}

Assim como acontece com a evolução da linguagem, novas tecnologias não costumam ser bem recebidas quando aparecem. Mudanças podem causar inseguranças e 
desconfortos. Inovações podem tirar-nos do nosso ambiente já conhecido e confiável. Dudeney, Hockly e Pegrum (2016, p. 16), discutindo os avanços tecnológicos, lembram que Sócrates temia a escrita, por achar que ela levaria a um "declínio da memorização e a um empobrecimento da discussão". Esse mesmo temor foi observado com a expansão da produção de livros, com o surgimento do telégrafo, com o advento do telefone, com a chegada da televisão. Cada nova tecnologia da comunicação poderia arruinar, no imaginário popular, aquela que a antecedeu.

Entretanto, praticamente incólumes à resistência da sociedade, novas tecnologias nunca deixaram de acompanhar a humanidade na passagem do tempo. Pensando nos últimos anos, se o século XX passou por uma revolução tecnológica sem igual, no século XXI, essas tecnologias avançaram com rapidez e amplitude, tornando-se mais acessíveis, sofisticadas e integradas, penetrando em quase todo o espectro social e transformando-o numa grande rede global dinâmica e conectada.

Nesse contexto, todas as esferas da estrutura social, como a política, a econômica e a do trabalho vivenciaram transformações estruturais que demandaram mudanças organizacionais determinadas. Na esfera educacional isso não aconteceu de forma diferente. Mudanças no currículo, nas práticas pedagógicas, nos relacionamentos estabelecidos nos espaços de ensino foram algumas das transformações exigidas para que a escola acompanhasse os avanços tecnológicos.

Ao pensarmos a relação ensino e tecnologia, remetemo-nos, atualmente, aos letramentos digitais, à necessidade de incorporação de recursos tecnológicos à sala de aula, ao desenvolvimento de competências tecnológicas por estudantes e docentes. Muito se discute atualmente a necessidade de uma formação docente que integre as tecnologias digitais às práticas de ensino-aprendizagem. Do professor é exigido que domine essas tecnologias para bem incorporá-las em práticas dinâmicas, modernas e significativas.

No contexto do ensino superior não é diferente. Diversas práticas são repensadas e procedimentos tradicionais são tomados como ultrapassados e ineficientes. Se no ensino presencial essas tecnologias ainda se apresentam de forma tímida e mais relacionadas a recursos audiovisuais utilizados pelo professor na exposição de uma aula, no ensino a distância elas se apresentam de maneira mais contundente, acompanhando o avanço das mídias digitais e a sofisticação das multimídias. 
Se no ensino presencial podemos optar pelo uso ou não de uma tecnologia ou outra, o ensino a distância acontece pela existência delas. Para Chaves (1999), o próprio conceito de ensino a distância relaciona-se à tecnologia, uma vez que são as tecnologias de telecomunicação e de transmissão de dados, voz e imagem, as responsáveis por contornar os efeitos ocasionados pela separação (no tempo e espaço) entre alunos e professores; mediação essa apresentada no Decreto no 9.057 de 25 de maio de 2017 (BRASIL, 2017, grifo nosso), que conceitua a Educação a Distância (EAD) no Brasil:

\begin{abstract}
Art. $1^{\circ}$ Para os fins deste Decreto, considera-se educação a distância a modalidade educacional na qual a mediação didático-pedagógica nos processos de ensino e aprendizagem ocorra com a utilização de meios $e$ tecnologias de informação e comunicação, com pessoal qualificado, com políticas de acesso, com acompanhamento e avaliação compatíveis, entre outros, e desenvolva atividades educativas por estudantes e profissionais da educação que estejam em lugares e tempos diversos.
\end{abstract}

Os primeiros dados registrados sobre a Educação a Distância, no Brasil, remetem ao início do século XX, quando o Jornal do Brasil registra, em 1904, na seção de classificados, um anúncio para formação de datilógrafos por correspondência. A partir da década de 1920, o rádio passou a ser, junto às correspondências, veículo mediador de cursos como francês, literatura francesa, esperanto, radiotelegrafia, telefonia, entre outros. Entre as décadas de 1960 e 1970, a televisão soma-se como meio eletrônico para educação a distância de jovens e adultos (ALVES, 2009).

Conforme Moore e Kearsly (2007), a Educação a Distância se caracteriza por cinco gerações diferentes: primeira - uso de correspondências (comunicação textual); segunda - ensino mediado por rádio e televisão; terceira - criação das universidades abertas; quarta - interação em tempo real, em cursos que se utilizam de áudio e videoconferência; quinta - uso das tecnologias da Internet, em que o processo de ensino-aprendizado ocorre on-line em classes e universidades virtuais.

Nessas diferentes fases, foi-se ampliando o alcance da Educação a Distância, à medida que apareciam tecnologias eletroeletrônicas que se popularizavam e passavam a fazer parte do cotidiano da sociedade. Cada um desses recursos, segundo explica Chaves (1999), inseriu novos elementos e abordagens à EAD. Se a tipografia permitiu que o livro impresso fosse exponencialmente distribuído, o rádio e a TV levaram som e imagem a lugares inóspitos. Da mesma forma, o surgimento do microcomputador e sua 
ampla utilização doméstica, e mais recentemente o acesso à Internet, permitiram que diversos recursos se incorporassem ao ensino a distância.

\begin{abstract}
O computador permitiu que o texto fosse enviado com facilidade a localidades remotas ou fosse buscado com facilidade em localidades remotas. $\mathrm{O}$ correio eletrônico permitiu que as pessoas se comunicassem assincronamente mas com extrema rapidez. Mais recentemente, o aparecimento de "chats" ou "bate-papos" permitiu a comunicação síncrona entre várias pessoas. E, mais importante, a Web permitiu não só que fosse agilizado o processo de acesso a documentos textuais, mas hoje abrange gráficos, fotografias, sons e vídeo. Não só isso, mas a Web permitiu que o acesso a todo esse material fosse feito de forma não-linear e interativa, usando a tecnologia de hipertexto (CHAVES, 1999, s/n).
\end{abstract}

No tocante ao ensino superior, embora iniciativas de implementação da educação a distância tenham surgido já na década de 1970, somente em 2005, o Ministério da Educação, a Associação Nacional dos Dirigentes das Instituições Federais de Ensino Superior (ANDIFES) e as Instituições participantes do Fórum das Estatais pela Educação, criaram o sistema Universidade Aberta do Brasil (UAB), oficializado pelo decreto 5.800, de 8 de julho de 2006 (PASSOS, 2018).

Um dos principais objetivos do Sistema UAB, explicitado já no inciso I do Parágrafo único do Artigo $1^{\circ}$ do decreto supracitado, é “oferecer prioritariamente, cursos de licenciatura e de formação inicial e continuada de professores da educação básica" (BRASIL, 2006). Para a efetivação desse objetivo, professores universitários assumiram novos papéis, em ambientes virtuais de trabalho, que exigiram e exigem desse profissional competências didático-pedagógicas que abarcam tanto o domínio de conteúdo, quanto a capacidade de utilizar as novas tecnologias na promoção de um ensino interativo, dinâmico e funcional.

O ensino superior a distância demanda, pela sua configuração, conforme dito, diferentes papéis docentes. Mill (2012), discutindo sobre o que é ser professor em ambientes virtuais, elenca tipos variados nesse contexto. Para o autor, o professorresponsável é aquele que se volta ao planejamento da disciplina; o professorconteudista, o que elabora materiais didáticos a serem utilizados na plataforma; o professor-formador acompanha e orienta os tutores; o professor-tutor faz a mediação entre professores e alunos no ambiente de ensino.

Vemos, pois, que não há uma simplificação do trabalho docente no ambiente virtual, ao contrário disso, há uma expansão das atribuições docentes. O professor passa a ser efetivamente mediador e norteador do conhecimento de um aluno que precisará ser 
mais autônomo e autodidata, características exigidas num ambiente de ensinoaprendizado que ocorre de maneira mais assíncrona que síncrona (na maioria dos casos).

Se de um lado há uma polivalência nas funções docentes, de outro, habilidades e competências são exigidas, também, dos alunos. No ensino presencial, muito da compreensão dos conteúdos acontece pela escuta, pelo que é transmitido pelo professor e debatido pela turma. Esses debates ocorrem entre os alunos que leem os textos sugeridos pelo professor e entre os que não leem também que, por inferência, captam as informações e inserem-se nas discussões apresentando seus pontos de vista. Na EAD, essa interação não se dá assim, nem mesmo nos fóruns. A construção do conhecimento dá-se em terreno mais solitário, o que exige maior nível de envolvimento, responsabilidade e disciplina.

A gerência do tempo é outro fator diferencial. No ensino presencial, a aula acontece num espaço/tempo determinado (algumas horas) compartilhado por todos os presentes. Os trabalhos em grupos, seminários e provas da mesma forma. Todo professor sabe que nesses eventos avaliativos há uma energia coletiva, uma inquietação que motiva até os mais dispersos a entrarem no "clima" da avaliação. Além do que, para esses eventos, há uma preparação que envolve as visitas à biblioteca e os encontros dos grupos de estudos. A gerência do tempo é de alguma forma uma responsabilidade compartilhada.

$\mathrm{Na} \mathrm{EAD}$, aulas, leituras, debates de textos e atividades ocorrem em outra dimensão temporal. Há, de um lado, mais liberdade para a organização do tempo, o que exige mais disciplina e compromisso. Normalmente, não há a necessidade de se estar presente no evento "aula", pois os materiais para leitura estão dispostos numa plataforma que pode ser consultada a qualquer horário do dia, a depender da disponibilidade do consulente. Essa maior autonomia com relação à gestão do tempo é uma vantagem para alunos mais aptos à autoaprendizagem.

\footnotetext{
Por suas características intrínsecas, por sua própria natureza, a EAD, mais do que as instituições convencionais de ensino superior, poderá contribuir para a formação inicial e continuada destes estudantes mais autônomos, já que a auto-aprendizagem é um dos fatores básicos de sua realização. (BELLONI, 2003, p. 39)
}

Além da autonomia, é necessário considerar a motivação como elemento essencial no processo de ensino-aprendizagem. Principalmente no ensino a distância, ela 
é fator decisivo para permanência e finalização dos cursos. Embora se relacione diretamente ao interesse e engajamento do próprio aluno nas atividades ofertadas, a motivação pode (e deve) ser estimulada por professores e tutores no ambiente da sala de aula, por meio de iniciativas que o integrem ao ambiente de aprendizado e o encorajem a participar e colaborar com o processo de construção do conhecimento.

Observamos, assim, que ao graduando da modalidade de ensino a distância são requisitadas algumas características que extrapolam a habilidade de manuseio de computadores e aplicativos. A escolha por um curso a distância, motivada pelas mais diferentes razões, já implica que a organização do tempo e as formas de estudar e se relacionar com coordenadores, professores e discentes acontecerá de forma diferente do que ocorreria no ensino presencial. De certo modo, o aluno já ingressa compreendendo que precisará manter uma postura mais ativa com relação a sua aprendizagem. Mas, o que acontece quando alunos do ensino presencial são catapultados para o ensino a distância?

A realidade vivenciada no ano de 2020, com a pandemia da Covid-19, resultou na suspensão de aulas presenciais em escolas e universidades, afetando mais de $70 \%$ dos estudantes do mundo, segundo a Unesco (2020). No Brasil, essa excepcional situação, levou inúmeras universidades a adotarem a educação remota emergencial, seguindo as diretrizes da Portaria N ${ }^{\circ}$ 343, de 17 de março de 2020 (BRASIL, 2020) que, dentre outras resoluções, autorizou já no artigo $1^{\circ}$, "a substituição das disciplinas presenciais, em andamento, por aulas que utilizem meios e tecnologias de informação e comunicação".

Em 20 de agosto de 2020, cerca de $80 \%$ das universidades federais brasileiras, conforme a ANDIFES, tinham aderido ao ensino remoto de emergência ou já se preparavam para o retorno das atividades utilizando o modelo remoto, em setembro desse mesmo ano (FURLAN, 2020).

Educação remota e Educação a Distância (EAD), embora possuam muitas semelhanças, não podem ser tomadas como a mesma modalidade de ensino. Anteriormente, discutimos alguns fatores que caracterizam a EAD, mas no que ela se distingue da educação remota? Conforme Hodges (2020 apud Arruda, 2020, p. 265), educação remota se diferencia da Educação a Distância, “pelo caráter emergencial que 
propõe usos e apropriações das tecnologias em circunstâncias especificas de atendimento onde outrora existia regularmente a educação presencial".

Ou seja, media-se ensino e aprendizagem por meio da tecnologia, mas para um público vindo das práticas do ensino presencial. Dentro de uma situação atípica e de crise, são criados meios e soluções para que atividades e conteúdos tradicionalmente planejados para o modelo presencial sejam transpostos para um formato on-line. Nesse sentido, podem ser usadas como ferramentas de ensino tanto as mais comuns da EAD, como arquivos de textos, vídeos e atividades assíncronas (tarefas, questionários, fóruns) quanto as que tentam se aproximar ao máximo da aula presencial, como as aulas síncronas, em ambientes virtuais, no formato de lives (ARRUDA, 2020).

Dentro desse universo, tanto professores quanto alunos, muitas vezes, dão os primeiros passos em plataformas que exigem habilidades tecnológicas específicas. Alguns alunos, por estarem familiarizados com suportes e ferramentas digitais, rapidamente têm-se adaptado à nova realidade, outros não. Alguns professores, por desenvolverem trabalhos em ambientes virtuais de aprendizagem, como o Moodle, o TelEduc, a AulaNet, por exemplo, navegam com mais facilidade pelas plataformas disponibilizadas por suas instituições de ensino, outros não. Para alguns desses sujeitos, o ambiente virtual de ensino é um espaço desconhecido, o que o torna extremamente desafiador.

Muitas questões, dentro desse contexto, podem, precisam e provavelmente serão discutidas ao longo dos próximos anos, que deverão dar conta de refletir sobre os impactos desse período inédito na realidade educacional brasileira. Nosso trabalho visa contribuir com essas reflexões, ao apresentar uma análise a respeito das percepções de alunos graduandos do curso de Letras da UFPB que, a partir do mês de junho de 2020, passaram a cursar disciplinas, oficinas, cursos livres e minicursos e a participar de seminários, fóruns e palestras no formato on-line. Buscamos observar as dificuldades vivenciadas na acomodação aos ambientes virtuais e compreender quais os maiores aprendizados obtidos ao longo dessa experiência.

\section{METODOLOGIA}


Nosso trabalho deteve-se à análise bibliográfica e documental. Baseando-nos nos dizeres de Bravo (1991), que entende documentos como toda realização produzida pelo homem que revela suas opiniões e ideias, consideramos o material colhido para análise como documentos, pois os textos produzidos por graduandos do curso de Letras traduzem suas leituras e interpretações de uma experiência vivenciada.

Os produtores dos textos analisados são alunos da modalidade presencial de um curso de Letras da UFPB que, assim como muitos outros estudantes do ensino superior, passaram a frequentar disciplinas na modalidade remota. Depois de cursarem dez semanas de uma disciplina da área da Linguística: Sociolinguística, na plataforma Moodle Classes, os alunos foram convidados a elaborar um texto que respondesse à questão: "Em comparação ao ensino presencial, quais foram as maiores vantagens e desvantagens do ensino remoto?” A seguir, apresentaremos a análise e interpretação dos textos produzidos.

\section{ANÁLISE E INTERPRETAÇÃO DOS DADOS}

Como dito, para realização desse trabalho, debruçamo-nos sobre 34 (trinta e quatro) produções textuais de graduandos de Letras da Universidade Federal da Paraíba. Esses alunos cursariam a disciplina de Sociolinguística no formato presencial no semestre letivo da UFPB que se iniciaria no mês de abril de 2020. A suspensão das aulas ocorrida pelo surto do novo Coronavírus (COVID-19) motivou que disciplinas que ocorreriam na modalidade presencial fossem ministradas na modalidade remota. Assim, professores e estudantes, após algumas semanas de cursos de capacitação para uso da plataforma Moodle Classes, passaram a utilizar espaços e ferramentas digitais pensadas para a continuidade do processo de ensino-aprendizagem.

A disciplina Sociolinguística ofertada no chamado "Calendário suplementar" foi desenvolvida, como supracitado, em dez semanas. Como avaliação final, foi pedida uma produção textual que motivasse os alunos a refletir sobre a experiência vivenciada, comparando-a com as vivências do ensino presencial.

Após leitura atenta das produções, selecionamos seis eixos temáticos considerados pelos informantes como vantagens ou desvantagens do ensino remoto. São eles: interação, autonomia, prazos, limitações tecnológicas, ambiente doméstico e 
letramentos digitais. Eles foram considerados mais relevantes pela frequência de aparecimento nos relatos. As referências das citações colhidas do material analisado aparecerão no seguinte formato: PT1, PT2, PT3... PTN, sendo PT (Produção Textual).

\section{INTERAÇÃO}

Se a autonomia na organização do tempo aparece ora como uma vantagem ora como uma desvantagem no ensino remoto, como veremos adiante, a falta de interação presencial é essencialmente uma desvantagem, conforme analisado nos textos lidos.

\footnotetext{
"Sinto saudades das risadas em momentos divertidos das aulas" (PT1)

"Senti falta de debates mais profundos, apesar dos fóruns, que despertassem mais curiosidades e clareza" (PT7)

“[...] no ensino presencial é possível uma maior interação, troca de diálogos, esclarecimento de dúvidas, pois às vezes até em um simples olhar, ou expressão que o discente faz, o professor percebe se ele entendeu ou não tal assunto" (PT15)

"Pode parecer bobagem, mas a falta da presença física e o contexto que a sala de aula promove faz com que a gente perca o "timing"' (PT17)

"Como desvantagem, considero a ausência do contato humano, da presença física do professor/a ao nosso lado, nos indicando, nos orientando e esclarecendo dúvidas mais de perto" (PT25)
}

Como podemos depreender das citações, há algo que não é possível transpor para o universo virtual: as trocas vivenciadas face a face. A falta desse "contato humano", seja físico ou verbal, ou mesmo por "olhares" e "expressões", deixa lacunas no processo de ensino-aprendizagem. No complexo espaço que é a da sala de aula não acontecem só a transmissão de conteúdos e a realização de exercícios avaliativos, acontecem aprendizados mútuos que surgem das dinâmicas relacionais entre professores e alunos, entre alunos e alunos.

A distância física no contexto da Educação a Distância chega a ser um fator modificador de comportamentos, interferindo significativamente na construção da comunicação entre os sujeitos envolvidos no processo. Cria-se, em alguns momentos, porque é próprio da comunicação escrita, uma excessiva formalidade que dificulta a construção de laços importantes para o processo do ensino. No ensino remoto, mesmo que a interação ocorra oralmente, por meio dos encontros assíncronos, há uma dificuldade na manutenção da participação e da motivação, o que pode ser ilustrado pela 
paulatina desativação de câmeras e áudios ocorrida ao longo de uma aula um pouco mais longa.

\section{AUTONOMIA}

Diversos estudos que se põem a refletir sobre o ensino a distância discutem a importância da disciplina e da capacidade de organização do tempo e dos métodos de estudos para que sejam obtidos bons resultados em cada etapa do ensino. Essa maior liberdade e autonomia podem, conforme observamos, ser uma vantagem ou uma desvantagem, segundo as impressões analisadas.

[...] a liberdade de poder definir em qual momento do dia ou da semana responder um questionário ou fazer uma produção textual permite uma adequação de horários que não ocorre no ensino presencial (PT7)

O ensino remoto proporciona algumas vantagens, uma delas é a organização individual, de acordo com a sua disponibilidade e seu próprio ritmo, especialmente, nas atividades assíncronas (PT 25)

O outro ponto que quero mencionar é a versatilidade quanto ao horário, pois tinha uma semana inteira para o desenvolvimento das atividades de forma que o aluno poderia escolher os horários mais propícios para a realização destas (PT30)

A vantagem que o ensino remoto tem é a liberdade de escolha do horário de estudo, poder assistir aos vídeos-aulas quantas vezes quiser e repeti-los quando necessário, para uma anotação (PT34)

Como comentado anteriormente, alunos que possuem um perfil mais autodidata e têm mais capacidade de organização adaptam-se mais facilmente ao ensino a distância. Imprimindo um ritmo próprio, planejam como distribuir o tempo entre as leituras e as atividades exigidas pelas disciplinas. Sem a obrigação de estar presentes num tempo e espaço determinados, podem encaixar os estudos da semana em horários que sejam mais propícios, a depender da realidade de cada um, podendo, como citado, repetir aulas gravadas ou realizar exercícios com mais tempo e tranquilidade.

Uma desvantagem é que, diferentemente do ensino presencial, o ensino remoto exige do estudante o estudo organizado e orientado por ele mesmo (PT3)

[...] o horário de estudo também se tornou uma desvantagem, pelo menos para mim, porque no ensino presencial fica mais definido e separado, temos horário para sair de casa e ir assistir a aula, a flexibilidade do ensino remoto deixa a gente um pouco disperso, mesmo que nos organizemos para estudar (PT29) 
A falta de um compromisso semanal materializado num encontro presencial de algumas horas (a aula) pode ser um fator desmotivador para alguns alunos. A ideia do encontro na sala de aula, em que se discutirão temas específicos exige dos alunos (pelo menos, alguns deles) que estejam preparados para aquela situação. Assim, cobram-se por realizar leituras e atividades para aquele momento.

Também já foi mencionado o papel dos estudos colaborativos realizados por grupos que se reúnem nos ambientes acadêmicos para trocar informações e descobertas a respeito de questões estudadas nas disciplinas. Mais uma vez aqui debate-se a importância da socialização, bastante cara para alunos que estudam melhor em companhia de outros. Assim, de alguma forma, a responsabilidade pela gestão das obrigações acadêmicas é compartilhada e esse fator pode ser decisivo para a permanência no curso para determinados perfis de alunos.

\section{PRAZOS}

Dentro das salas virtuais, o aluno costuma encontrar um cronograma de leituras e atividades a serem realizadas que, por não acontecerem em um tempo e espaço específicos, mas dentro de um prazo maior estipulado (que pode ser ampliado a depender da boa vontade do professor), figuram como uma das maiores vantagens do ensino remoto, conforme verificado.

\footnotetext{
A vantagem foi ter mais tempo para se dedicar as atividades (PT1)

No ensino remoto podemos realizar atividades com um prazo maior diferentemente do presencial, podemos usar como exemplo a "prova" que sempre é feita em uma única tarde no ensino presencial, mas no remoto temos mais tempo e podemos pensar mais sobre as respostas (PT3)

[...] ter uma quantidade maior de tempo para se estudar o assunto foi a vantagem (PT22)

[...] um maior tempo para realizar a leitura dos textos, o tempo de envio das respostas dos exercícios, sem toda aquela pressão das provas que temos no ensino presencial (PT28)
}

Uma das características do ensino remoto são as possibilidades diversificadas de atividades síncronas. Se no ensino presencial, seminários figuram entre os métodos avaliativos preferidos por permitirem um conjunto de ações: leitura de textos, resumo de tópicos, exposição de conteúdos oralmente e debates sobre temas diversos; no ensino a distância, esse modelo de avaliação praticamente não é usado e no ensino remoto, nos atrevemos a dizer, ele tende a ser evitado por exigir condições muito específicas para 
sua realização. Assim, outras atividades são pensadas para avaliar os aprendizados e motivar a participação ao longo das semanas e, como dito, essas atividades podem se estender ao longo de uma semana ou mais.

Embora o método avaliativo prova, citado nas produções textuais 3 e 28, não tenha sido realizado na disciplina e por isso sua ausência figure como uma vantagem do ensino remoto, esse método pode e é utilizado tanto no ensino a distância quanto no ensino remoto. Inclusive, na $\mathrm{EAD}$, a aplicação das provas costuma ser um dos momentos presenciais dos cursos. No ensino remoto pode se dar por meio de testes online a serem respondidos num prazo estabelecido.

\title{
LIMITAÇÕES TECNOLÓGICAS
}

O ensino remoto acontece vinculado aos recursos tecnológicos. Baixar um arquivo, visualizar uma videoaula, responder a um questionário on-line, participar de um fórum, de um chat, de uma live é possível por meio de um computador, um smartphone ou um tablet, e de uma conexão à Internet. Mesmo a realização de atividades como a produção de textos, que podem ocorrer off-line, necessita de softwares editores de textos, pois resumos, resenhas, roteiros dirigidos ou relatórios são comumente pedidos em formato Word ou PDF.

Se esses recursos podem falhar mesmo em condições ideais de acesso: computadores com processadores de última geração, novas e avançadas tecnologias de Internet; para aqueles que não possuem essas tais condições (a maioria da população brasileira), a falta ou precariedade desses recursos pode ser um dos maiores obstáculos ao acesso a essa modalidade de ensino.

\begin{abstract}
Em meio a tantas desigualdades sociais, acredito que a principal desvantagem do ensino remoto é de que vários alunos, que por sinal são dedicados e participativos, não puderam participar das disciplinas ofertadas. O motivo primordial é por falta de acesso à internet. Infelizmente, são muitos problemas relacionados ao ensino remoto por vivermos em um país desigual, preconceituoso e onde a falta de recursos tecnológicos para a aprendizagem é notória (PT25)
\end{abstract}

Para alunos que vivem em comunidades rurais e mais afastadas, realidade de parte dos alunos que integraram a disciplina estudada, o acesso à internet pode ser um agente dificultador ou mesmo um empecilho à participação nas atividades ofertadas, 
principalmente aquelas que exigem uma maior capacidade de transmissão de dados, como uma videoaula, por exemplo.

[...] outros pontos potencialmente prejudiciais são: a dependência da internet, seja ela por sinal de operadora ou provedor, dependência de energia e aparelhos digitais. Perceba, caso qualquer um desses itens tenha um problema grave, pode inviabilizar completamente o ensino. (PT12)

No meu caso, tenho acesso a uma boa internet e disponho de um bom computador, e mesmo assim houve momentos de instabilidade com a internet (PT14)

Outro ponto desfavorável do ensino remoto é que para ter acesso a ele necessitamos estar sempre conectados à internet, o que muitas vezes não é possível, pois nem todos têm acesso a esta rede, não têm itens como celular, computador etc. para participar das aulas, e quem tem enfrenta problemas de conexão, que impossibilita o envio de atividades, a realização de pesquisas, entre outras coisas, como meu caso, que enfrentei alguns problemas nesse sentido, embora tenha conseguido entregar as atividades no prazo (PT15)

A dependência do bom funcionamento da plataforma do Classes para que a gente pudesse usá-la corretamente, assim como na hora de enviar os nossos exercícios da disciplina; dependência da internet, que no meu caso, nem sempre a minha estava funcionando bem, então eu tinha que decidir um bom horário para poder usá-la (PT29)

Nos depoimentos, compreendemos que, para a efetiva realização do ensino a distância, não é suficiente a posse de equipamentos físicos, os hardwares, nem mesmo o acesso à Internet, pois, se não há velocidade ideal para navegação, várias ferramentas digitais de ensino, por mais dinâmicas e didáticas que sejam, não chegam até o aluno, principalmente aquelas que se propõem a mobilizar uma maior participação da turma, como os chats e os encontros síncronos, por exemplo.

\section{AMBIENTE DOMÉSTICO}

A pandemia do Covid-19 imprimiu novos cotidianos a diversas cidades brasileiras. Principalmente entre abril e junho do corrente ano, na Paraíba, diversas atividades profissionais foram suspensas, estabelecimentos foram temporariamente fechados e a população incentivada a permanecer em suas residências, obedecendo aos protocolos de isolamento social. O ambiente doméstico passou a ser o espaço de trabalho de vários profissionais que migraram para o modelo home office, ou trabalho remoto.

Contudo, nem todos gozam de espaços estruturados e bem equipados para a realização desses trabalhos. Professores e alunos, muitas vezes, para dar continuidade a 
seus projetos nessa nova rotina, adaptaram ambientes que, dependendo da realidade de cada um, são compartilhados por outros membros da família. Misturam-se, nesse cenário, atividades domésticas e atividades acadêmicas: cuidados com crianças e idosos, visualização de videoaulas, limpeza da casa, leituras de textos, compras de supermercado, realização de exercícios avaliativos.

\footnotetext{
[...] de acordo com minha realidade e de meus colegas, destaco como dificuldades enfrentadas [...] o ambiente diário em que estamos inseridos, pois há muitas pessoas em casa e muito barulho, fato que dificulta a leitura de textos para a realização das atividades (PT3)

[...] acho que o ensino remoto dificultou [...] na questão da concentração, já que em casa é um pouco difícil, para quem mora com muitas pessoas, por conta do barulho (PT9)

[...] estar em um ambiente caseiro é extremamente prejudicial à concentração, conversas, veículos, tarefas domésticas, todas estas coisas acabam por dificultar a concentração ou mesmo dispersá-la completamente (PT11)

[...] senti as desvantagens do ensino remoto em relação [...] à falta de estar estudando no ambiente universitário, visto que em casa nem sempre o ambiente é tão propicio devido a ter que conciliar estudos com outras obrigações familiares, entre outros fatores. (PT18)

Em casa, sempre tem alguma distração, algo para fazer, sem falar do barulho que muitas vezes tem na rua (PT29)
}

O ambiente universitário, não apenas a sala de aula, mas os espaços de convivência, como as bibliotecas e as salas de estudos, pode ser o refúgio para muitos alunos que buscam concentração para realização de atividades acadêmicas. Casas cheias, barulhos e distrações aparecem como fatores que dificultam a aprendizagem. Se em contexto de normalidade os alunos podem usar os espaços universitários para os estudos, principalmente nos contraturnos de seus cursos, nesse momento precisam utilizar os diversos cômodos da casa para isso. Nesse contexto, não só os ambientes físicos são compartilhados, mas os equipamentos também. Algumas vezes, um só computador deve servir a todos os familiares que se revezam para dar conta das demandas.

\section{LETRAMENTOS DIGITAIS}

Foi bastante recorrente em nossa pesquisa lermos que o ensino remoto é uma oportunidade para o desenvolvimento dos letramentos digitais. Embora a maioria dos universitários esteja familiarizada com o manuseio de equipamentos eletrônicos e 
ferramentas digitais, para muitos, as plataformas e interfaces do ensino remoto eram terrenos desconhecidos.

\begin{abstract}
As maiores vantagens foram que nos permitimos descobrir novas formas de estudo, buscar novas estratégias que condizem com o momento das aulas remotas, acredito que muito do que se aprendeu no calendário suplementar ficará nos períodos presenciais, como por exemplo confecções de vídeos, fóruns, atividades mais objetivas, e a possibilidade de se reunir mesmo de forma remota nas aulas síncronas (PT14)

As maiores vantagens do ensino foram permitir novas possibilidades de conhecimento, como a aprendizagem de ferramentas tecnológicas, dos usos das plataformas, apresentando novos meios de enviar trabalhos, de responder questionários, de se interagir virtualmente através de fóruns (PT15)

As maiores vantagens foram as novas experiências educacionais, já que nunca tinha utilizado da tecnologia dessa maneira para o estudo, e por meio dessa experiência obter conhecimento foi de grande aproveitamento (PT19)

[...] essa modalidade de ensino abriu os horizontes para aprendermos a dominar as tecnologias digitais, a inovarmos com plataformas já existentes e a explorarmos nossa criatividade nas produções das atividades remotas (PT25)
\end{abstract}

Dentro de salas virtuais acontecem os eventos tradicionais do ensino: disponibilização de materiais para leituras, exposição de conteúdo, discussões, pesquisas, exercícios. Contudo, nesse ambiente, esses elementos ganham novos formatos. Para o acesso a materiais de leitura, pode-se fazer downloads ou lê-los em janelas рор-ир, para a visualização de um vídeo é necessário clicar em links que direcionarão o material para um ambiente de visualização, para responder a um questionário, é necessária uma leitura da tela para localizar questões e assertivas, para enviar uma produção textual, é importante que se tenha noção de editores de textos e compactação de tamanhos de arquivos.

Embora as interfaces gráficas dessas ferramentas de ensino sejam cada vez mais intuitivas, é necessário o desenvolvimento de habilidades que são apuradas com o uso. Essas habilidades envolvem, dentre outras coisas, localizar, ler e compreender modelos não lineares ou hipertextuais. O aprendizado desses recursos e a possibilidade de agregar esses conhecimentos e utilizá-los, futuramente, no ensino presencial, foram compreendidos com uma das vantagens da experiência com o ensino remoto.

\title{
CONSIDERAÇÕES FINAIS
}

Após leitura atenta das 34 (trinta e quatro) produções textuais que compõem o corpus dessa pesquisa, observamos que a experiência com o ensino remoto, mesmo 
desafiadora, foi considerada relevante. Como ponto positivo ou vantagem do ensino remoto, em comparação ao ensino presencial, observamos prioritariamente a questão da maior autonomia com relação à organização das atividades, embora para alguns, essa liberdade possa ser um fator negativo.

Das 34 (trinta e quatro) produções analisadas, em 18 (dezoito) delas aparece como vantagem o fato de os alunos poderem gerir com maior liberdade seu tempo de estudo. Como segunda maior vantagem, destacam a ampliação dos letramentos digitais. Em 32\% dos textos (11 produções), foi considerado de grande valor o conhecimento de novas ferramentas digitais que, conforme apontam, podem ser incorporadas ao ensino presencial futuramente. A questão dos prazos ampliados também foi destacada. Em $23 \%$ dos textos (8 produções), os prazos para realização das atividades apareceram como elemento positivo no ensino remoto. Ter mais tempo para realização de leituras e atividades, conforme citado, diminui a pressão e torna o processo mais tranquilo.

Como fator negativo, ou desvantagem do ensino remoto em comparação ao ensino presencial, apareceu de forma significativa a falta de interações presenciais. Em $70 \%$ dos textos (24 produções), a ausência das relações face a face, propriedade das aulas presenciais, prejudica o processo de ensino-aprendizagem. Além disso, aparecem como desvantagens do ensino remoto a precariedade de recursos tecnológicos e a falta de um ambiente de estudo adequado. Em $41 \%$ dos textos (14 produções), as limitações tecnológicas figuram como um dos principais agentes dificultadores do ensino remoto, principalmente a ausência de Internet de qualidade. Por fim, um ambiente doméstico tumultuado foi citado como fator negativo em 8 produções (23\% dos textos).

Outras questões, embora tenham aparecido de forma pontual e não frequente, merecem ser destacadas. Como exemplo, temos a "contenção de gastos", apresentada por dois alunos como um ponto positivo do ensino remoto. Para eles, poder estudar em casa permitiu economizar recursos financeiros, algo particularmente importante no momento de instabilidade financeira vivenciada. Como desvantagem do ensino remoto, a "instabilidade emocional" foi mencionada em uma produção, em que encontramos o seguinte depoimento:

Como estudante, posso falar que a instabilidade emocional influenciava muito no meu rendimento diário. Quando algo em casa não estava bem, quando mais um conhecido pegava o vírus, quando mais uma pessoa conhecida morria por causa disso, quando pessoas da família perdiam o emprego, era impossível a concentração total nas aulas e isso refletia muito no rendimento. (PT32) 
Em nossa análise, esse depoimento dimensiona a complexidade do tema. Para mensurarmos todas as questões envolvidas no processo de ensino-aprendizagem desse novo momento não podemos nos ater somente às questões tecnológicas, didáticopedagógicas ou econômicas. Cada membro da comunidade acadêmica, seja aluno, professor ou técnico, dentro de sua realidade, tem vivenciado esse processo de uma forma muito particular. Compreender melhor essas histórias e essas realidades é fundamental para que possamos ter uma ideia, pelo menos superficial, dos impactos causados pela pandemia de 2020 na educação superior brasileira.

\section{Referências}

ALVES, J. R. M., A História da EAD no Brasil. In: LITTO, F.M.; FORMIGA. M. (Org.). Educação a Distância: o estado da arte. Vol. 1. São Paulo: Pearson Education do Brasil, 2009.

ARRUDA, E. P. Educação remota emergencial: elementos para políticas públicas na educação brasileira em tempos de Covid-19. Em Rede: Revista de Educação a Distância. Porto Alegre. v. 7. n. 1, 2020, p. 257-275.

BELLONI, M. L. Educação a Distância. Campinas-SP: Autores Associados, 2003.

BRASIL. Decreto 9.057, de 25 de maio de 2017. Regulamenta o artigo 80 da Lei no 9.394, de 20 de dezembro de 1996, que estabelece as diretrizes e bases da educação nacional. Diário Oficial [da] República Federativa do Brasil. Brasília, DF, 25 dez. 2017. Disponível em: http://www.planalto.gov.br/ccivil_03/_Ato20152018/2017/Decreto/D9057.htm\#art24. Acesso em: 25 ago. 2020.

BRASIL. Decreto 5.800, de 8 de julho de 2006. Dispõe sobre o Sistema Universidade Aberta do Brasil - UAB. Disponível em:

http://www.planalto.gov.br/ccivil_03/_ato2004-2006/2006/decreto/d5800.htm Acesso em: 25 ago. 2020.

BRASIL. Portaria 343, de 17 de março de 2020. Dispõe sobre a substituição das aulas presenciais por aulas em meios digitais enquanto durar a situação de pandemia do Novo Coronavírus - COVID-19. Disponível em: https://www.in.gov.br/en/web/dou/-/portarian-343-de-17-de-marco-de-2020-248564376. Acesso em: 26 ago. 2020.

BRAVO, R. S. Técnicas de investigação social: Teoria e ejercicios. 7 ed. Madrid: Paraninfo, 1991. 
CHAVES, E. Conceitos Básicos: Educação a Distância. EdutecNet: Rede de Tecnologia na Educação, 1999. Disponível em: http://www.edutecnet.com.br/. Acesso em: 25 ago. 2020.

DUDENEY, G.; HOCKLY, N.; PEGRUM, M. Letramentos digitais. Tradução de Marcos Marcionilo. São Paulo: Parábola Editorial, 2016.

FURLAN, P.V. Andifes informa que $80 \%$ das universidades federais aderiram ao ensino remoto de emergência. UFMS. Disponível em: https://cpnv.ufms.br/andifesinforma-que-80-das-universidades-federais-aderiram-ao-ensino-remoto-de-emergencia/ Acesso em: 25 ago. 2020.

MILL, D. Docência virtual: uma visão crítica. Campinas: Papirus, 2012.

MOORE, M.; KEARSLEY, G. Educação a distância: uma visão integrada. São Paulo: Cengage Learning, 2007.

PASSOS, M. L. S. Educação a distância [recurso eletrônico]: breve histórico e contribuições da Universidade Aberta do Brasil e da Rede e-Tec Brasil. Vitória: edição do autor, 2018.

UNESCO. Educação: da interrupção à recuperação. Disponível em: https://pt.unesco.org/covid19/educationresponse. Acesso em: 26 ago. 2020.

Recebido em: 30/08/2020

Aceito em: 18/10/2020 